\title{
Postdoctoral Individual National Research Service Award
}

National Cancer Institute

\section{Source}

National Cancer Institute. Postdoctoral Individual National Research Service Award. NCI

Thesaurus. Code C20001.

To provide support to promising Fellowship Applicants with the potential to become productive, independent investigators in scientific health-related research fields relevant to the missions of participating NIH Institutes and Centers. 